\title{
An internet of things framework for real-time aquatic environment monitoring using an Arduino and sensors
}

\author{
Md. Monirul Islam ${ }^{1}$, Mohammod Abul Kashem ${ }^{1}$, Jia Uddin ${ }^{2}$ \\ ${ }^{1}$ Department of Computer Science and Engineering, Dhaka University of Engineering and Technology, Gazipur, Bangladesh \\ ${ }^{2} \mathrm{AI}$ and Big Data Department, Endicott College, Woosong University, Daejeon, South Korea
}

\begin{tabular}{l} 
Article Info \\
\hline Article history: \\
Received Dec 31, 2020 \\
Revised Jul 13, 2021 \\
Accepted Jul 25, 2021 \\
\hline
\end{tabular}

Keywords:

Arduino and sensors

Fish farming

Real-time monitoring system Internet of things

\begin{abstract}
Aquaculture is the farming of aquatic organisms in natural, controlled marine and freshwater environments. The real-time monitoring of aquatic environmental parameters is very important in fish farming. Internet of things (IoT) can play a vital role in the real-time monitoring. This paper presents an IoT framework for the efficient monitoring and effective control of different aquatic environmental parameters related to the water. The proposed system is implemented as an embedded system using sensors and an Arduino. Different sensors including $\mathrm{pH}$, temperature, and turbidity, ultrasonic are placed in cultivating pond water and each of them is connected to a common microcontroller board built on an Arduino Uno. The sensors read the data from the water and store it as a comma-separated values (CSV) file in an IoT cloud named ThingSpeak through the Arduino microcontroller. To validate the experiment, we collected data from 5 ponds of various sizes and environments. After experimental evaluation, it was observed among 5 ponds, only three ponds were perfect for fish farming, where these 3 ponds only satisfied the standard reference values of $\mathrm{pH}$ (6.5-8.5), temperature $\left(16-24{ }^{\circ} \mathrm{C}\right)$, turbidity (below $\left.10 \mathrm{ntu}\right)$, conductivity $(970-1825 \mu \mathrm{S} / \mathrm{cm}$ ), and depth (1-4) meter. At the end of this paper, a complete hardware implementation of this proposed IoT framework for a real-time aquatic environment monitoring system is presented.
\end{abstract}

This is an open access article under the $\underline{C C B Y-S A}$ license.

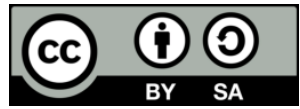

\section{Corresponding Author:}

Jia Uddin

AI and Big Data Department, Endicott College, Woosong University

Daejeon, South Korea

Email: jia.uddin@wsu.ac.kr

\section{INTRODUCTION}

Fish is one of the most useful sustenance on the earth. It is stacked with huge enhancements including protein and supplement D. Fish is moreover an uncommon wellspring of omega-3 unsaturated fats, which are incredibly huge for our body and psyche. Fish has loaded down with various enhancements that a large number of individuals are deficient. This consolidates great protein, iodine, and various supplements and minerals. Oily species are often considered the most helpful. That is because of the oily fish. Salmon, trout, sardines, fish, and mackerel are higher in fat-based enhancements. This fuses supplement D, a fatdissolvable enhancement that various people are lacking. The oily fishes furthermore gloat omega-3 unsaturated fats are vital for the ideal body, brain, and unequivocally associated with a diminished threat of various ailments [1]. Respiratory disappointments and strokes are the two most ordinary explanations behind unexpected passing on the planet [2]. Fish is seen as one of the most heart-sound sustenance that we can eat. Clearly, various colossal observational assessments show that people who eat fish regularly have a lower threat of respiratory disappointments, strokes, and passing from coronary disease [3]. The omega-3 fat 
docosahexaenoic destructive (DHA) is especially huge for the cerebrum and eye progression [4]. It is often recommended that pregnant and breastfeeding women eat enough omega-3 unsaturated fats [5]. Various observational examinations show that people who eat more fish have all the more moderate movements of mental lessening [6].

For these significant factors, pisciculture or fish farming is very much important for more producing fish and human beings. Before cultivating fish, it is mandatory to know which factors affect water quality parameters including $\mathrm{pH}$, turbidity, water depth level, temperature, etc. Water quality is dictated by factors like temperature, straightforwardness, turbidity, water tone, carbon dioxide, $\mathrm{pH}$, alkalinity, hardness, unionized smelling salts, nitrite, nitrate, essential profitability, biochemical oxygen demand (BOD), and microscopic fish populace [7].

The job of these parameters cannot be disregarded for keeping a sound oceanic climate and for the creation of adequate fish food life forms in lakes for expanding fish creation [8]. Consequently, there is the need to guarantee that, these ecological components are appropriately overseen and managed for good endurance and ideal development of fish. Temperature, $\mathrm{pH}$, turbidity, BOD, conductivity and dissolved oxygen (DO) among these factors of water have much important role for surviving fish species [9]. The rest of the paper is arranged as follows. A literature review is stated in section 2. In section 3, the proposed architecture is discussed. The experimental setup and detailed result analysis are presented in section 4 . Finally, the paper is concluded in section 5.

\section{LITERATURE REVIEW}

This section discusses a segment of actions linked to the embedded system using internet of things (IoT) for pisciculture. There are many IoT-based water inspection frameworks that have been proposed. Some of them are effectively utilized for fish homesteads and hydroponics focuses [10]. An IoT system is proposed for selecting the fish species using various sensors' values including mq7, $\mathrm{pH}$, turbidity, ultrasonic, and temperature sensors [11]. The main limitation of this paper is not describing the real-time scenarios of the pond's environments. Islam et al. [12] proposed an IoT system for fish farming thoroughly. However, no real-time values and scenarios are generated for the fish farmers. An IoT-based water quality monitoring system is proposed for aquaculture in Mekong Delta [13]. The narrowness of this system is to cultivate one fish type called pangasius at five farms. Wireless sensor network based system is proposed for monitoring water quality and fish behavior during the feeding process [14]. It is designed for tank water only. Periyadi et al. [15], an IoT system is mentioned for fish farming. The restriction of this system that it is designed for only fish named guppy fish and only two sensors are used including $\mathrm{pH}$ and salinity sensor. Alam et al. [16] proposed a data-driven approach for monitoring the aquatic environment for the ocean. The limitation of the model, it creates a stochastic model for predicting the actual ocean data without using IoT devices. Ahmed et al. [17] discussed the parameters only of aquatic environment without any IoT devices. A remote monitoring system is proposed using the IoT in [18]. An IoT system has proposed using only two sensors for fish farming in Bangladesh [19]. It is not appropriate for detecting all quality factors of the water. In Lee et al. [20], temperature, $\mathrm{pH}$, DO levels, and ultrasonic sensors are used for monitoring the tank water. The narrowness of this system is conducted without any real-time scenarios. A mobile app for monitoring water quality is presented in [21], where two sensors including $\mathrm{pH}$ and temperature are used. The limitation of the model is that it is not suitable for measuring all factors of water. Considering the limitations of the state-ofart models, in this paper, we propose an IoT framework for real-time aquatic environment monitoring using Arduino and sensors. To evaluate the proposed architecture, we have utilized five ponds of various sizes and specifications.

\section{PROPOSED ARCHITECTURE}

Figure 1 presents an illustration of the suggested architecture. In the IoT framework, we used four sensors including $\mathrm{pH}$ sensor (model 03SEN14), temperature sensor (model DS19B20), turbidity sensor (model 3305SEN1), and ultrasonic sensor (model HC-SR04). Every sensor is connected with an Ethernet shield by a various jumper on the breadboard. Then the Ethernet shield is linked with an Arduino Uno. Using the Rest-API, a cloud server is connected with this framework.

\subsection{IoT framework}

In the IoT framework, we used 4 sensors for measuring real-time data of each pond water. They are$\mathrm{pH}$ sensor, temperature sensor, turbidity sensor, and ultrasonic sensor. In Figure 2, the hardware used in the proposed IoT framework is presented. We have employed a temperature control sensor. It has an impact on the conduct, management, development and spread of fisheries government aid. The $\mathrm{pH}$ is an evaluation which addresses the solution's acidity or alkalinity. It is an activity level of hydrogen ion in solution. The 
number ranges from 0 to 14 . It is deemed neutral when its value is 7 . When above 7 , the solution is alkaline, and below 7, then acidic water is considered. The $\mathrm{pH}$ range for fish viability in a pond is often between 6.5 and 8.5. It is the major survival element. That is why we use this sensor in our system. The ultrasonic sensor can detect the depth level of water. Every fish species cannot live on one level. Fishes live in upper level or middle level or lower level. For measuring this point, we used this sensor in our system. Turbidity is the unwanted something in the water that hinders to production of fish species. For measuring this issue, we used a turbidity sensor. In the proposed architecture, we have used an ethernet shield and Arduino Uno [22]. Arduino Uno may be simply connected to the internet with ethernet shield. This shield allows Arduino to transfer data from sensors with internet connections to a cloud server.

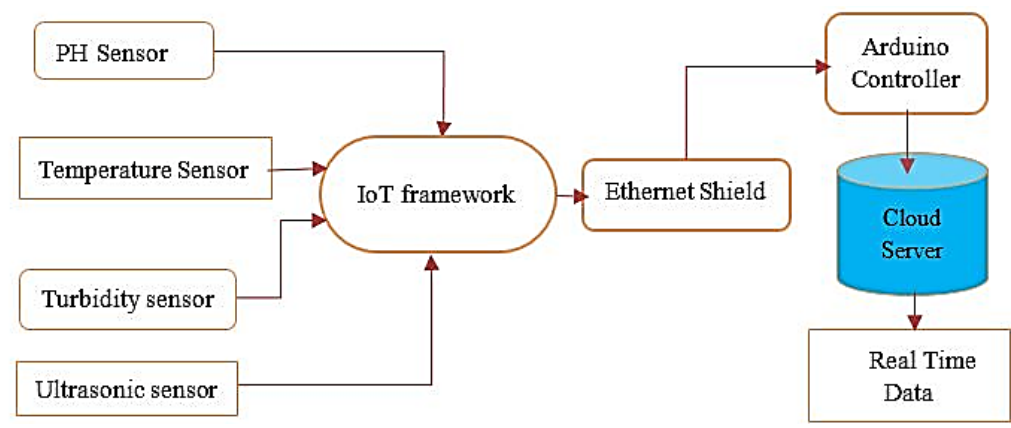

Figure 1. Illustration of suggested methodology

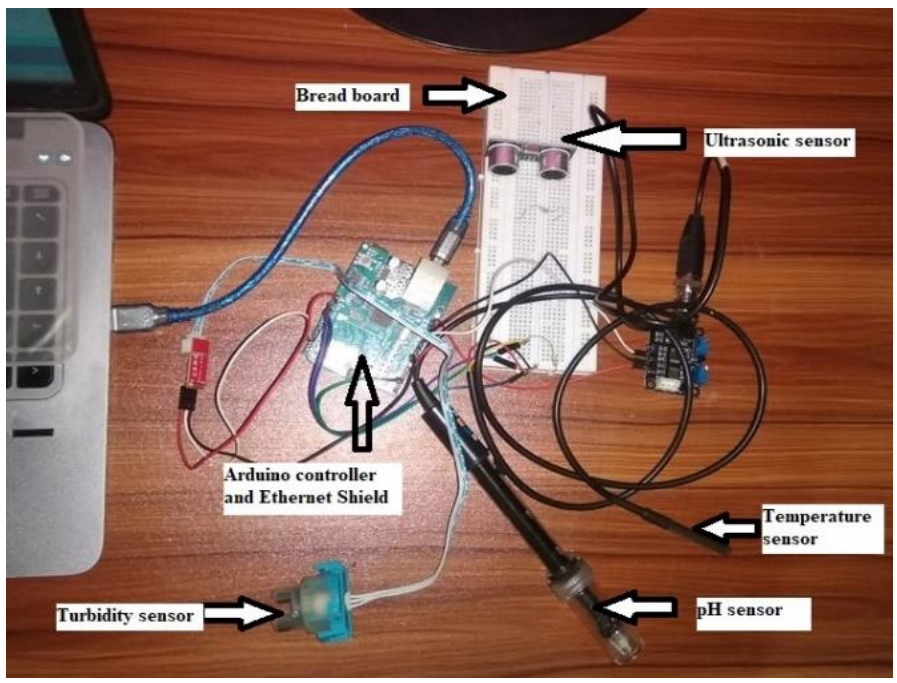

Figure 2. Utilized hardware of our system-turbidity sensor, temperature sensor, pH sensor, ultrasonic sensor, Arduino Uno, and ethernet shield

\subsection{Cloud server and real-time data}

The real-time data were stored in the ThingSpeak IoT server. This is a free cloud server for permitting to gather and store sensor information in the cloud and create IoT applications. It is stored in comma-separated values (CSV), extensible markup language (XML), and JavaScript object notation (JSON) format. In the experiments, we have stored the data for each pond for 4 hours 10 minutes. Among the 250 minutes' data, we have considered data after 3 minutes as we only consider the data for the stable circuit.

\section{EXPERIMENTAL SETUP AND RESULT ANALYSIS}

We have considered 5 ponds for monitoring the quality of water using the proposed IoT system. In the experimental evaluation, we do programming in Arduino suite software. Due to the lack of portability of the hardware, we have collected water from the ponds using a bucket from all the ponds, which is displayed 
in Figure 3. Table 1 illustrates the specifications of all ponds. The depth of the pond should not be less than 1 meter or more than 5 meters, the best depth is 2 meters. After collecting, we dipped our all sensors into the water for getting real-time data. As experimenting sample, Figure 4 shows the experiment of $\mathrm{pH}$ values, turbidity values, and temperature values, respectively in water for analysis of water quality.

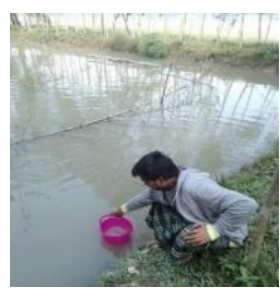

(a)

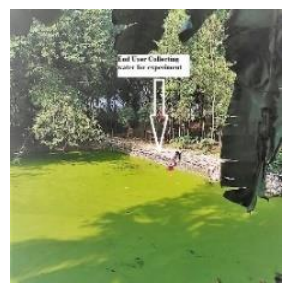

(b)

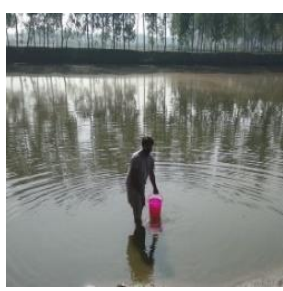

(c)

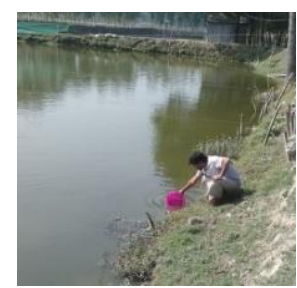

(d)

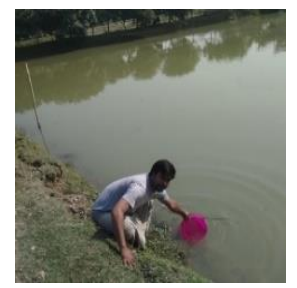

(e)

Figure 3. Water collection from all ponds: (a) pond 1, (b) pond 2, (c) pond 3, (d) pond 4, and (e) pond 5

Table 1. Specification of all ponds

\begin{tabular}{cccccc}
\hline Term & Pond 1 & Pond 2 & Pond 3 & Pond 4 & Pond 5 \\
\hline Length $(\mathrm{m})$ & 26 & 52 & 105 & 156 & 40 \\
Width $(\mathrm{m})$ & 17 & 30 & 35 & 80 & 20 \\
Water depth(m) & $1-2$ & $1-2$ & $1-2$ & $2-4$ & $1-3$ \\
\hline
\end{tabular}

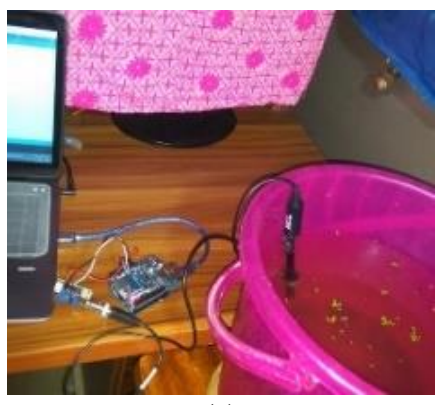

(a)

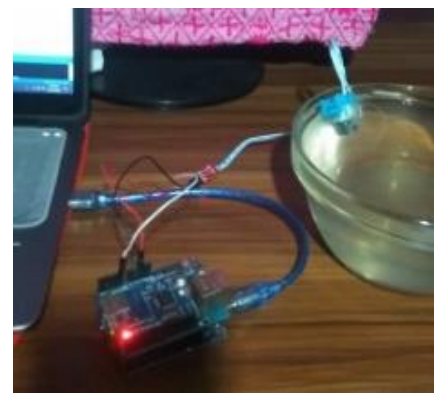

(b)

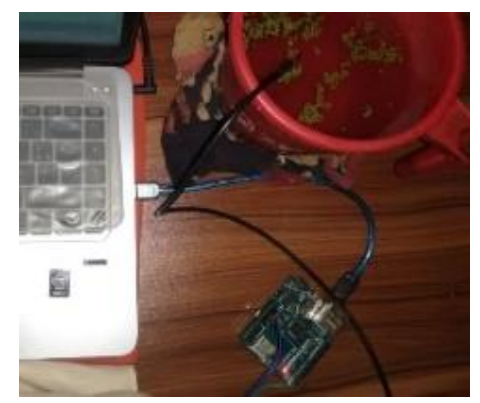

(c)

Figure 4. Experimenting water of (a) $\mathrm{pH}$, (b) turbidity, and (c) temperature value in some ponds

$\mathrm{pH}$ sensors for all experiments are tested on between 8:50-9:30 pm on 20 December 2020, on between 11:18-11:50 am on 21 December 2020, on between 2:00-2:50 pm on 20 December 2020, on between 6:00-6:50 pm on 20 December 2020, and on between 2:30-3:20 pm on 22 December 2020 for pond 1 , pond 2 , pond 3 , pond 4 , and pond 5, respectively. We take 4 hours 10 minutes from 3 days in all experiments. In the Arduino suite, we keep the baud rate 9600 for serial begin function for all experiments.

The experiment of the turbidity sensors of all experiments is on between 10:00-10:50 am on 23 December 2020, on between 12:00-12:50 pm on 23 December 2020, on between 2:10-3:00 pm on 23 December 2020, on between 4:00-4:50 pm on 23 December 2020, and on between 5:20-6:10 pm on 23 December 2020 for all ponds, respectively. We take 4 hours 10 minutes from 1 day in all experiments.

Temperature sensors for all experiments are tested on between 3:00-3:50 pm on 25 December 2020, on between 4:10-5:00 am on 25 December 2020, on between 10:00-10:50 am on 25 December 2020, on between 11:09-11:59 am on 25 December 2020, and on between 12:20-1:10 pm on 25 December 2020 in all ponds, respectively. We take 4 hours 10 minutes from 1 day for temperature experiment in all experiments. In the Arduino suite, we keep the baud rate 9600 for serial begin function for all experiments.

Figure 5 shows the graph of the $\mathrm{pH}$ value of the real-time data. The range of $\mathrm{pH}$ value is 6.02-8.39, 8.57-8.87, 6.00-7.83, 6.51-8.30 and 3.84-3.95 for pond 1, pond 2, pond 3, pond 4, and pond 5, respectively. The $\mathrm{pH}$ range of pond 1 is suited for fish production according to the standard reference value, 6.5-8.5 [23]. The received $\mathrm{pH}$ value, 8.57-8.87 from pond 2 is greater than the ideal value. Therefore, this pond is not perfect for fish farming. In pond 3, the range of $\mathrm{pH}$ is 6.00-7.83. It is almost near to ideal range, 6.5-8.5. Pond 4 also provides acceptable values of $\mathrm{pH}$. The range of $\mathrm{pH}$ values is not perfect for fish farming for pond 5 . This causes to die for fish species. It is a death point for acidity. 


\section{pH Value}

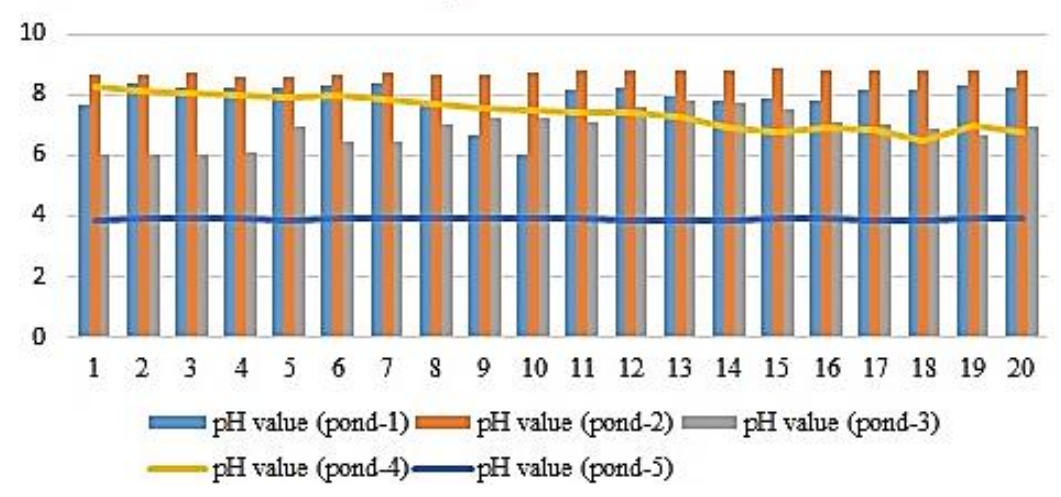

Figure 5. Real-time value of $\mathrm{pH}$ of all experiments

Figure 6 displays a graph of real-time values of turbidity from all of the experiments. The range of turbidity values is 3.55-3.57 NTU, 3.41-3.50 NTU, 3.31-3.49 NTU, 3.60-3.62 NTU, and 3.56-3.58 NTU for pond 1 , pond 2 , pond 3 , pond 4 , and pond 5 , respectively. The acceptable turbidity range is below 10 NTU for fish farming [24]. Figure 6 dictates that all received values of turbidity from all experiments are acceptable. Figure 7 displays graph of real-time values of temperature from all of experiments. The range of temperature values is $17.50-17.75{ }^{\circ} \mathrm{C}, 17.75-18.00{ }^{\circ} \mathrm{C}, 20.87-21.06{ }^{\circ} \mathrm{C}, 21.06-21.44{ }^{\circ} \mathrm{C}$, and $21.06-21.25{ }^{\circ} \mathrm{C}$ for pond 1 , pond 2 , pond 3 , pond 4 , and pond 5, respectively. The overall acceptable range of temperature for pond is $16-24{ }^{\circ} \mathrm{C}$ [25]. The received real-time sensor of all experiments is perfect for fish farming.

Turbidity Value

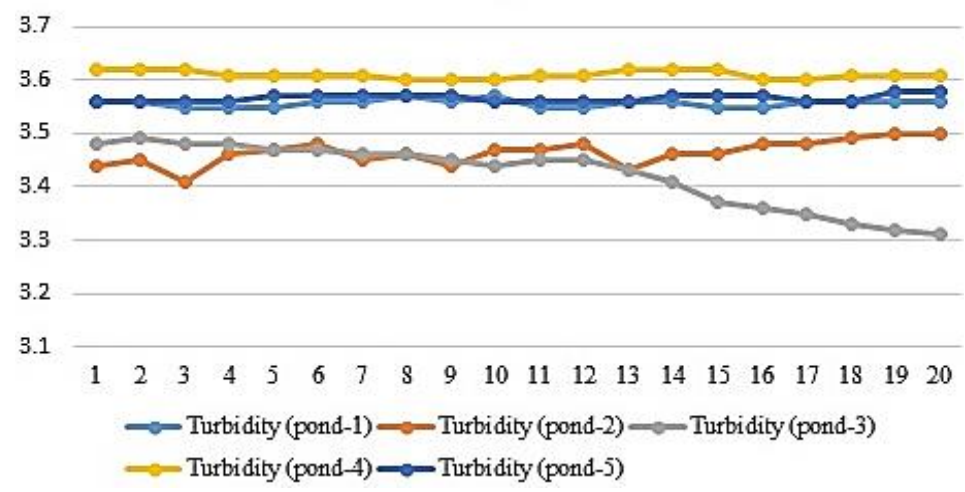

Figure 6. Real-time value of turbidity of all experiments

Conductivity is a helpful parameter to assess the virtue of water. It is subject to the ionic fixation and water temperature [26]. Temperature in a water body is directly related to its conductivity. At $25{ }^{\circ} \mathrm{C}$, has a specific conductance of $1,413 \mathrm{mmhos} / \mathrm{cm}$ but at $20{ }^{\circ} \mathrm{C}$ and $30^{\circ} \mathrm{C}$, the values are 1,273 and $1,547 \mathrm{mmhos} / \mathrm{cm}$, respectively [27]. When water temperature increases, conductivity increases. Conductivity readings can rise by $2-4$ percent for each $1{ }^{\circ} \mathrm{C}$ increase. By raising ion mobility, the temperature impacts conductivity. The ideal range of it is $970-1825 \mu \mathrm{S} / \mathrm{cm}[28]$.

Figure 8 displays graph of real-time values of conductivity from all of experiments. The range of conductivity values is $989-1003 \mu \mathrm{S} / \mathrm{cm}, 1003-1017 \mu \mathrm{S} / \mathrm{cm}, 1179-1190 \mu \mathrm{S} / \mathrm{cm}, 1193-1215 \mu \mathrm{S} / \mathrm{cm}$, and 1190 $1203 \mu \mathrm{S} / \mathrm{cm}$ for pond 1 , pond 2, pond 3, pond 4, and pond 5, respectively. The received real-time sensor of all experiments is perfect for fish farming. Table 2 illustrates the summary of all received values for each pond. According to the ideal range of all parameters, pond 1, pond 3, and pond 4 are eligible for fish farming. The pond 2 is not perfect for cultivation fish. Because of the $\mathrm{pH}$ value, 8.57-8.87 is higher than the ideal values. It is the point of the slow growth of fish. The pond 5 is not suited for the lower $\mathrm{pH}$ value, 3.84-3.95. This causes fish death. That is why, we could not give suggestions for pond 1 and pond 2 to fish farmers. 


\section{Temperature Value}

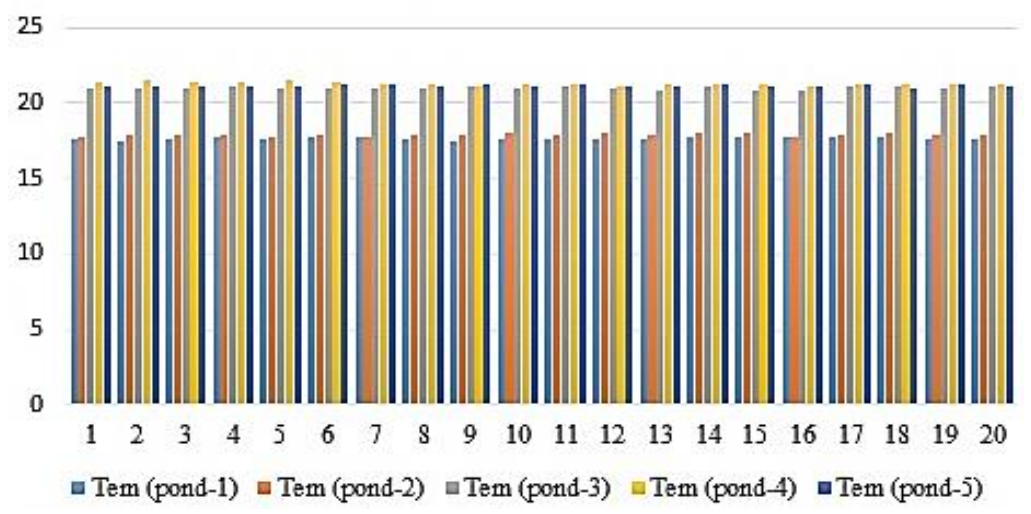

Figure 7. Real-time value of temperature of all experiments

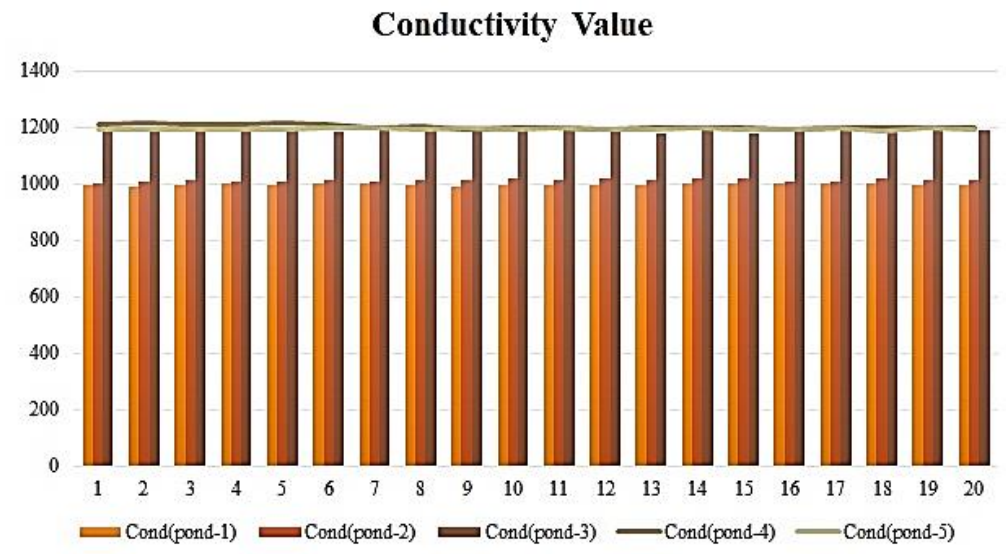

Figure 8. Real-time value of conductivity of all experiments

Table 2. Received values for suggesting pond

\begin{tabular}{ccccccc}
\hline Pond & $\mathrm{pH}$ & Temperature $\left({ }^{\circ} \mathrm{C}\right)$ & Turbidity $(\mathrm{ntu})$ & Depth $(\mathrm{m})$ & Conductivity $(\mu \mathrm{S} / \mathrm{cm})$ & Remarks \\
\hline Pond 1 & $6.02-8.39$ & $17.50-17.75$ & $3.55-3.57$ & $1-2$ & $989-1003$ & Recommended \\
Pond 2 & $8.57-8.87$ & $17.75-18.00$ & $3.41-3.50$ & $1-2$ & $1003-1017$ & No Recommended \\
Pond 3 & $6.00-7.83$ & $20.87-21.06$ & $3.31-3.49$ & $1-2$ & $1179-1190$ & Recommended \\
Pond 4 & $6.51-8.30$ & $21.06-21.44$ & $3.60-3.62$ & $2-4$ & $1193-1215$ & Recommended \\
Pond 5 & $3.84-3.95$ & $21.06-21.25$ & $3.56-3.58$ & $1-3$ & $1190-1203$ & No recommended \\
\hline
\end{tabular}

\section{CONCLUSION}

In this paper, an automated IoT framework for real-time data monitoring is proposed and successfully instigated using diverse sensors and circuits as demonstrated in different figures. We experimented using 5 scenarios for obtaining real-time values including $\mathrm{pH}$, temperature, conductivity, depth, and turbidity values. After analyzing the real-time values, pond 1, pond 3 and pond 4 are perfect in fish farming and pond 2 and pond 5 are not perfect for fish farming. That is why, end-user can cultivate fish in pond 1 , pond 3, and pond 4 . For pond 2 and pond 5, a farmer can take any step for utilizing these ponds for fish farming later. As the proposed model is automatically controlled, it will help the farmers to properly monitor their ponds. The implementation enables the sensor to provide data to the ThingSpeak server. The results show that the system presented is capable of assessing water quality indicators in real time, transmitting data to the Cloud, and informing users of water quality. In future, the proposed architecture may be tested with more aquatic environment parameters by targeting specific fish species.

\section{ACKNOWLEDGEMENTS}

This research is funded by Woosong University Academic Research in 2021. 


\section{REFERENCES}

[1] C. H. S. Ruxton, S. C. Reed, M. J. A. Simpson, and K. J. Millington, "The health benefits of omega-3 polyunsaturated fatty acids: A review of the evidence," Journal of Human Nutrition and Dietetics, vol. 17, no. 5, pp. 449-459, Oct. 2004, doi: 10.1111/j.1365277X.2004.00552.x.

[2] World Health Organization. "The top 10 causes of death." WHO. 2020. https://www.who.int/news-room/fact-sheets/detail/thetop-10-causes-of-death (accessed Nov. 5, 2020).

[3] S. Buscemi et al., "Habitual fish intake and clinically silent carotid atherosclerosis," Nutr J., vol. 13, no. 2, Jan. 2014, doi: 10.1186/1475-2891-13-2.

[4] J. C. McCann and B. N. Ames, "An overview of evidence for a causal relation between iron deficiency during development and deficits in cognitive or behavioral function," The American Journal of Clinical Nutrition, vol. 85, no. 4, pp. 931-945, Apr. 2007, doi: 10.1093/ajen/85.4.931.

[5] B. Koletzko et al., "The roles of long-chain polyunsaturated fatty acids in pregnancy, lactation and infancy: review of current knowledge and consensus recommendations," J Perinat Med, vol. 36, no. 1, pp. 5-14, 2008, doi: 10.1515/JPM.2008.001.

[6] M. C. Morris, D. A. Evans, C. C. Tangney, J. L. Bienias, and R. S. Wilson, "Fish consumption and cognitive decline with age in a large community study," Arch Neurol, vol. 62, no. 12, pp. 1849-1853, Dec. 2005, doi: 10.1001/archneur.62.12.noc50161.

[7] B. Anita, and D. Pooja, "Water quality guidelines for the management of pond fish culture," International journal of environmental sciences, vol. 3, no. 6, pp. 1980-2009, Dec. 2013, doi: 10.6088/ijes.2013030600019.

[8] G. A. M. Abdalrahman et al., "Review on wastewater treatment ponds clogging under artificial recharge: Impacting factors and future modelling," Journal of Water Process Engineering, vol. 40, pp. 101848, Apr. 2021, doi: 10.1016/j.jwpe.2020.101848.

[9] M. Sato et al., "Measurements of aquatic pollutant loading amounts using the automatic composite sampler and automatic sampler," Bulletin of Aichi Environmental Research Center (Japan), vol. 7, pp. 37-43, 1979.

[10] C. Encinas, E. Ruiz, J. Cortez, and A. Espinoza, "Design and implementation of a distributed IoT system for the monitoring of water quality in aquaculture," 2017 Wireless Telecommunications Symposium (WTS), pp. 1-7, Jun. 2017, doi: 10.1109/WTS.2017.7943540.

[11] M. M. Islam, J. Uddin, M. A. Kashem, F. Rabby, and M. W. Hasnat, "Design and implementation of an IoT system for predicting aqua fisheries using arduino and KNN," Intelligent Human Computer Interaction, Lecture Notes in Computer Science, vol. 12616, pp. 108-118, Feb. 2021, doi: 10.1007/978-3-030-68452-5_11.

[12] M. M. Islam, M. A. Kashem, and F. Jui, “Aqua fishing monitoring system using IoT devices," Int. J. Innov. Sci. Eng. Technol, vol. 6, no. 11, pp. 109-114, 2019.

[13] L. V. Q. Danh, D. V. M. Dung, T. H. Danh, and N. C. Ngon, "Design and deployment of an IoT-based water quality monitoring system for aquaculture in mekong delta," International Journal of Mechanical Engineering and Robotics Research, vol. 9, no. 8, pp. 1170-1175, Aug. 2020.

[14] L. Parra, S. Sendra, L. Garcia, and J. Lloret, "Design and deployment of low-cost sensors for monitoring the water quality and fish behavior in aquaculture tanks during the feeding process," Sensors (Basel), vol. 18, no. 3, Mar. 2018, doi: $10.3390 / \mathrm{s} 18030750$.

[15] Periyadi, G. I. Hapsari, Z. Wakid, and S. Mudopar, "IoT-based guppy fish farming monitoring and controlling system," TELKOMNIKA Telecommunication, Computing, Electronics and Control, vol. 18, no. 3, pp. 1538-1545, 2020, doi: 10.12928/TELKOMNIKA.v18i3.14850.

[16] T. Alam, G. M. Reis, L. Bobadillah, and R. N. Smith, "A data-driven deployment approach for persistent monitoring in aquatic environments," 2018 Second IEEE International Conference on Robotic Computing (IRC), 2018, pp. 147-154, doi: 10.1109/IRC.2018.00030.

[17] M. Ahmed, M. O. Rahman, M. Rahman, and M. A. Kashem, "Analyzing the quality of water and predicting the suitability for fish farming based on IoT in the context of Bangladesh," International Conference on Sustainable Technologies for Industry 4.0, 2019, pp. 1-5, doi: 10.1109/STI47673.2019.9068050.

[18] P. Sun and Y. Chen, "Aquiculture remote monitoring system based on internet of things," 2019 International Conference on Robots and Intelligent System (ICRIS), 2019, pp. 187-190, doi: 10.1109/ICRIS.2019.00056.

[19] D. M. M. Khan, "An IoT based smart water monitoring system for fish firming in Bangladesh," 5th International Electronic Conference on Water Sciences session New sensors, New Methods and Technologies, New Approaches, 2020, doi: 10.3390/ECWS-5-08044.

[20] J. Lee, A. Angani, T. Thalluri, and K. J. Shin, "Realization of water process control for smart fish farm," 2020 International Conference on Electronics, Information, and Communication (ICEIC), 2020, pp. 1-5, doi: 10.1109/ICEIC49074.2020.9051285.

[21] N. A. J. Salih, I. J. Hasan, and N. I. Abdulkhaleq, "Design and implementation of a smart monitoring system for water quality of fish farms," Indonesian Journal of Electrical Engineering and Computer Science (IJEECS), vol. 14, no. 1, pp. 45-52, 2019, doi: 10.11591/ijeecs.v14.i1.pp44-50.

[22] F. Rahman, I. J. Ritun, M. R. A. Biplob, N. Farhin, and J. Uddin., "Automated aeroponics system for indoor farming using arduino," 2018 Joint 7th International Conference on Informatics, Electronics and Vision (ICIEV) and 20182 nd International Conference on Imaging, Vision \& Pattern Recognition (icIVPR), 2018, pp. 137-141, doi: 10.1109/ICIEV.2018.8641026.

[23] M. M. Islam, M. A. Kashem, and J. Uddin, "Fish survival prediction in an aquatic environment using random forest model," IAES International Journal of Artificial Intelligence (IJ-AI), vol. 10, no. 3, pp. 614-622, 2021, doi: doi: 10.11591/ijai.v10.i3.pp614-622.

[24] Fondriest Environmental, Inc. "Turbidity, total suspended solids and water clarity," Fundamentals of Environmental Measurements. Jun. 13, 2014. https://www.fondriest.com/environmental-measurements/parameters/water-quality/turbidity-totalsuspended-solids-water-clarity/ (accessed Jun. 4, 2021).

[25] Pond Informer, "Pond water temperature guide (best pond thermometers)," Pond Informer, 2019. https://pondinformer.com/pondwater-temperature-guide/ (accessed Jun. 4, 2021).

[26] G. K. Dinesh, M. Karthik, and R. Rajakumar, "Study of seasonal water quality assessment and fish pond conservation in Thanjavur, Tamil Nadu, India,” J. Entomol. Zool. Stud, vol. 5, no. 4, pp. 1232-1238, 2017.

[27] C. E. Boyd. "Electrical conductivity of water, part 1 (Professor Boyd: Principles and measurement of an important production parameter)." Global Aquaculture Alliance. https://www.aquaculturealliance.org/advocate/electrical-conductivity-water-part-1/ (accessed May 18, 2021).

[28] M. A. Halim, S. Sharmin, H. M. H. Rahman, M. M. Haque, M. S. Rahman, and M. S. Islam, "Assessment of water quality parameters in baor environment, Bangladesh: A review," International Journal of Fisheries and Aquatic Studies, vol. 6, no. 2, pp. 269-263, 2018. 


\section{BIOGRAPHIES OF AUTHORS}

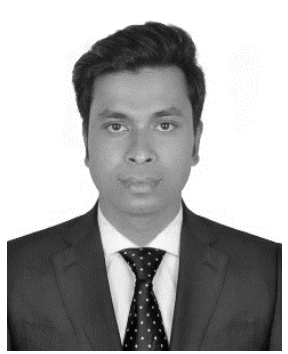

Md. Monirul Islam (iD 8d SC P has been studying as an M.Sc. in Engineering Student, Department of Computer Science and Engineering (CSE), Dhaka University of Engineering \& Technology (DUET), Gazipur-1700, Bangladesh. He has completed B.Sc. in engineering degree in CSE in the year 2017 from Pabna University of Science and Technology (PUST), Pabna-6600, Bangladesh. Currently, he is at Uttara University (UU) as a full-time lecturer since 3rd February 2020. Field of interest: Machine learning/Deep learning, Data science. He can be contacted at email: monir.duet.cse@gmail.com.

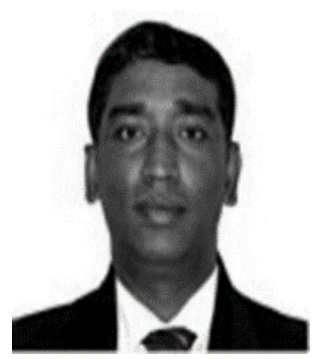

Mohammod Abul Kashem (ID SII SC P has been serving as an Professor, Department of Computer Science and Engineering (CSE) and Additional Director, Planning \& Development, Dhaka University of Engineering \& Technology (DUET), Gazipur-1700, Bangladesh. He got Post Doctorate (ULL, France), PhD (LPNU, Ukraine), M.Eng. \& B.Eng. (SULP, Ukraine). Field of interest: Internet of Things, Cyber Physical System, The Challenges, Approaches and Used Techniques of CPS for Manufacturing in Industry 4.0, CPS of collaborative value network for manufacturing, Multi Agent System for Industry and Critical Mission. He can be contacted at email: drkashemll@duet.ac.bd.

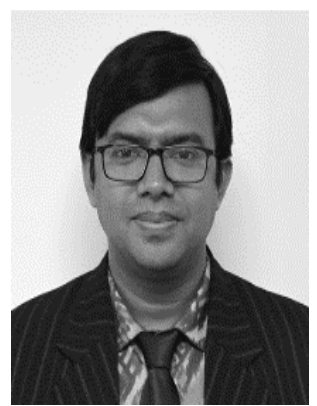

Jia Uddin (D) 8. SC P is as an Assistant Professor, AI and Big Data Department, Endicott College, Woosong University, Daejeon, South Korea. He received Ph.D. in Computer Engineering from University of Ulsan, South Korea, M.Sc. in Electrical Engineering (Specialization: Telecommunications), Blekinge Institute of Technology, Sweden, and B.Sc. in Computer and Communication Engineering, International Islamic University Chittagong, Bangladesh. He was a visiting faculty at School of computing, Staffordshire University, United Kingdom. He is an Associate Professor (now on leave), Department of Computer Science and Engineering, Brac University, Dhaka, Bangladesh. His research interests are Industrial Fault Diagnosis, Machine Learning/Deep Learning based prediction and detection using multimedia signals. He can be contacted at email: jia.uddin@wsu.ac.kr. 